\title{
International Days at the United Nations: Expanding the Scope of Diplomatic Histories
}

\author{
Monika Baár \\ Leiden University \\ m.k.baar@hum.leidenuniv.nl
}

\begin{abstract}
The article argues that more thorough scholarly engagement with the United Nations' international days has the potential for expanding the scope of diplomatic histories. It first provides a taxonomy of UN years by illuminating their repertoire, dynamics and peculiarities. Next, it discusses instances of how UN days are communicated to the public, emphasizing the role of media and celebrity diplomacy. Subsequently, the article demonstrates the crucial contribution of NGOs, policy makers, and professionals who, as "outside-insiders" form the "Third UN." Lastly, the article advances the argument that in order to obtain a more comprehensive account of UN days, another group of actors should be identified. These are comprised of organizations and individuals who are complete outsiders, but nevertheless contribute to the UN's "marketplace of ideas" - a group that may be designated the "Fourth UN."
\end{abstract}

\section{Keywords}

international days - UN days - digital diplomacy - United Nations media - celebrity diplomacy - the Fourth United Nations

In 1947 the General Assembly of the United Nations passed a resolution proclaiming 24 October as United Nations Day, to mark the day on which the

1 The author acknowledges the support of the ERC Consolidator Grant Rethinking Disability under grant agreement number 648115 . She also wishes to thank Jason Pronyk 
Charter of the United Nations came into force in 1945. Since then this day has been "devoted to the making known to the peoples of the world the aims and achievements of the United Nations and to gaining their support for the work of the United Nations." ${ }^{2}$ In the following seventy years dozens of comparable days were added to the UN's agenda, and in the last two decades this growth has been particularly steady. As of January 2019, the UN calendar lists no fewer than 159 such occasions and a slight further increase may be expected in the future.

On the one hand, this trend may justify worries about the potentially counterproductive effect of an over-crowded UN calendar. On the other, it elucidates the dual purpose of UN days: in addition to serving to bind the international community around more widely-known issues, they also contribute to the diversification of global governance by drawing attention to lesserknown or less-popular topics that could otherwise remain invisible. Take for example, the most recent addition, World Braille Day: it was celebrated for the first time as an official UN observance on January 4, 2019 (while it had been observed already earlier outside the UN) with the aim to raise awareness about the importance of Braille for approximately 1.3 billion people living with vision impairment. ${ }^{3}$ At a time when great hopes are being invested in technological advancement and media announcements triumphantly substantiate the claim that the restoration of vision may become a possibility in the near future, this new observance serves as a powerful reminder that for the time being, traditional methods and "solutions" offer the only alternative for the overwhelming majority of the world's blind and visually impaired population.

The aim of this concluding article to the special issue is to showcase the potentials which the study of UN days may offer for writing new diplomatic histories and in a more specific context for writing new histories of the United Nations. If UN observances have remained generally understudied in literature, this holds particularly true for international days. In fact, few studies have even selectively, let alone systematically, examined their history, significance and impact. This is by no means surprising: from among the genre of observances, international days are the most extraordinarily varied in nature and since they

and Balbir Singh for providing valuable insights that cannot be gleaned from the official documents.

2 https://www.un.org/ga/search/view_doc.asp?symbol=A/RES/168(II) (accessed June 30, 2019).

3 There appears to be little consistency in the designation of these events: some of them are labelled as UN days, others are called International Days or World Days, sometimes interchangeably. 
reoccur annually, it presents a significant challenge to trace their extremely diffuse and elusive trajectories. In light of this lacuna, this article cannot aim for a more systematic analysis. Instead, it seeks to point to the promise and relevance of UN days for writing histories that can revise our understanding of the form and substance of diplomacy by demonstrating their scope and the diversity of actors involved. In particular, the assessment of UN days throws new light on the role of non-state actors, and their quasi-official and unofficial contributions to diplomacy. The scholarly engagement with the international days also resonates with the objective to write histories of the UN which are interested in demarcating the organization's place "in international as well as world history as a site of cultural contestation, influence, continuity, and change." These studies are less interested in the historicization of the UN and more in its significance as a site for reconsidering a wide range of intersecting historiographies. ${ }^{4}$ These include postcolonialism, development, international relations, civil rights and social movements, just to name a few.

Given the limited literature on the topic, it may be useful to provide first a taxonomy of UN days by illuminating their repertoire, dynamics and peculiarities. How do they come into being, what are their underlying principal themes and why are they placed on a certain day? What is their overall role in global governance and public diplomacy, and why is it so difficult to asses their impact? Next, the article discusses instances of how international days are communicated to the public. By doing so it points to the potential that these days offer for enhancing our knowledge of the UN's new media and communication strategies, including social media and celebrity diplomacy. Subsequently, the article demonstrates the crucial role of NGOS, policy makers, and professionals who, as "outside-insiders" form the "Third UN," in addition to the "First UN" comprising the member states and the "Second UN" including the secretariats. Last but not least, the article advances the argument that in order to obtain a more comprehensive account of the agents, trajectories and dynamics of UN days, another group of actors should be identified who fall outside the actors represented by "Third UN." These are comprised of organizations and individuals who are outsiders, but nevertheless contribute to the UN's soft power with ideas that have the potential to shape the world - a group that may be designated the "Fourth UN." The ultimate ambition of this explanatory chapter on UN days is to call for an understanding of diplomacy that pays due attention to the domain of digital diplomacy acknowledges contributors from

4 Sluga, Glenda, and Sunil Amrith. "New Histories of the United Nations." Journal of World History 19 (3) (2008), 274. 
very heterogeneous agents who would remain undetectable if approached exclusively via the lenses of traditional diplomacy.

UN days may be initiated by a host of actors: international and national organizations, politicians, professional bodies, policy makers, NGOs and individuals. As in the case of other observances, they become approved on a consensual basis by member states and are proclaimed by the General Assembly or alternatively, by one of the UN's specialized agencies. While the United Nations' official website offers no definition for international weeks, years and decades, it provides one for days:

International days are occasions to educate the general public on issues of concern, to mobilize political will and resources to address global problems, and to celebrate and reinforce achievements of humanity. Each international day offers many actors the opportunity to organize activities related to the theme of the day. Organizations and offices of the United Nations system, and most importantly, governments, civil society, the public and private sectors, schools, universities and, more generally, citizens, make an international day a springboard for awareness-raising actions. $^{5}$

The same section explains that these observances are aligned with the UN's principal fields of action: the maintenance of international peace and security, the promotion of sustainable development, the protection of human rights, and the guarantee of international law and humanitarian action. A number of these observances are closely associated with the UN's history and therefore enjoy a particularly high status; in a certain sense the organization possesses symbolic "ownership" over them. The most significant one is the above-mentioned 24 October, United Nations Day, which marks the entry into force of the UN Charter in 1945. In 1971 the United Nations Assembly even proposed, albeit without success, that member states observe this day in the form of a public holiday. Comparable in significance is Human Rights Day on 10 December which observes the anniversary of the acceptance of the Universal Declaration of Human Rights by the General Assembly. Other days

5 https://www.un.org/en/sections/observances/why-do-we-mark-international-days/ (accessed June 30, 2019). 
remind the world of the dangerous nature of humanitarian work, for instance, the event dedicated to Solidarity with Detained and Missing Staff Members (March 25), which is held on the anniversary of the 1985 abduction of UNRWA staff member Alec Collet by a gunman. Another set of UN days are dedicated to victims of tragic episodes in world history - these include the slave trade, the two world wars, the Holocaust and the genocide in Rwanda. Some of these cherish the legacy of exceptional individuals, for example the International Day for the Right to the Truth Concerning Gross Human Rights Violations and for the Dignity of Victims which takes place on March 24. On that day in 1980, Archbishop Oscar Romero, a fearless denouncer of human rights violations and "the voice of the voiceless population," was murdered in civil-war-ridden El Salvador while celebrating a mass.

Initially exclusive to the $\mathrm{UN}$, these observances became isomorphically diffused to the UN's specialized agencies, which pursue international days in alliance with their mandate of social and labor diplomacy, cultural and health diplomacy. ${ }^{6}$ The ILO administers observances which emphasize the significance of socio-economic rights. Among these is the International Day for the Eradication of Poverty on October 17, which has been observed since 1992. It commemorates a gathering that took place in 1987 at the Trocadero in Paris, where the Universal Declaration of Human Rights was signed in 1948. Organized by Father Joseph Wresinski, an emblematic advocate of the rights of those living in extreme poverty, it was attended by over 100,000 people and its highlight was the unveiling of a commemorative stone. Further ILO-supported observances include the Day Against Child Labour (June 12) and the International Day of Happiness (March 20), the latter emphasizing that indicators of economic performance such as GDP figures cannot alone describe the quality of life and promoting a holistic approach to development.

International days focusing on culture, science and the environment typically receive support from UNESCO. Among them are observances dedicated to every official UN language. These days seek to safeguard diversity, multilingualism and cultural rights, and they are also supported by concrete projects, such as UNEsco's World Atlas of Languages and Atlas of World Languages in Danger. An increasing number of UN days focus on environmental issues, ranging from biodiversity, tsunami awareness, asteroids, migratory birds and the remembrance of victims of chemical welfare. Lastly, science, science education and communication also belong to UNESCO's remit; they are represented by events such as the International Day of Women and Girls in Science, Human Space Flight and World Radio Day.

6 Drori, Gili S. “United Nations' Dedications: A World Culture in the Making?" International Sociology 20 (2) (2005), 188. 
The WHO hosts the largest number of days among the UN's specialized agencies and many of them call attention to the consequences of a disease: tuberculosis, cancer, AIDS, malaria and diabetes, just to name a few. Others are related to disabilities, such as autism, Down syndrome and albinism. Still others focus on hygienic and societal problems: for example, World Toilet Day reminds the global public of the fact that $60 \%$ of the world's population has no access to toilets at all. World Health Day (April 7) and the recently introduced Universal Health Coverage Day (December 12) convey more general messages - the latter also acts as a reminder that half of the world lacks access to basic health services.

In certain cases, the UN co-opted an already existing "tradition": it would have been definitely counterproductive to observe International Women's Day on any date other than 8 March, which had been earmarked for this cause and had been celebrated in many places of the world ever since the early twentieth century. In a similar way, the reason why World Refugee Day, celebrated since 2010, was chosen to take place on June 20 is that in many countries this day had already been observed as African Refugees Day. On other occasions, the designation of a specific date has symbolic significance: Down Syndrome Day was chosen to take place on 21 March with reference to chromosome 21 (trisomie vingt-et un) which causes the condition. Some observances are scheduled on a specific day due to practical and mundane considerations. A case in point is World AIDs Day, which has been held since 1988 and which was the brainchild of James W. Bunn and Thomas Netter, two public information officers for the Global Programme on AIDS at the World Health Organization in Geneva. They suggested holding World AIDs Day on December 1 because they expected that this would help maximize its coverage by Western news media, as the date was sufficiently long after the US elections, but before the Christmas holidays. ${ }^{7}$ A number of UN international days were established in order to create continuity for the representation of a theme to which a year and/or a decade had also been dedicated. Among these is the International Day of Disabled Persons (December 3), which came into being in 1993 to ensure the continuation of mandate of the International Year of Disabled Persons (1981) and the subsequent International Decade of Disabled Persons (1983-1992).

While all UN observances, irrespective of their duration, share the same principal aims, UN days can ensure the greatest degree of continuity and

7 https://www.npr.org/2011/12/01/143017936/how-world-aids-day-began?t=1564005790148 (accessed June 30, 2019). 
widest repertoire thanks to their annual themes. These allow for the adjustment, diversification or intensification of their "original" remit (as set in the UN resolution). For example, the annual theme of World AIDS Day in 2006 included "Stop AIDs. Keep the Promise": this message was designed to encourage political leaders to keep their commitment to achieve AIDs prevention. Other themes focused on the specific trajectories of different age and gender groups: youth, girls and women, children, families and men. The same theme may also be repeated over a longer period of time. For example, both in 2012 and 2014 educational and social justice aspects were in focus with the theme: "Getting to Zero: Zero new HIV infections. Zero deaths from AIDs-related illness. Zero discrimination."

A myriad of events take place on UN days, some of which bolster professional engagement, while others seek to communicate the message of observances through press conferences, exhibitions, poster competitions, social media campaigns and a lot more. The limelight that UN days attract presents ideal conditions for the launching of major scientific reports on designated themes. ${ }^{8}$ One of the best-known instances is the annual Report on the Global HIV/AIDS Epidemic, a foremost reference source of epidemiological information. This has been published on the above-mentioned World AIDs Day since 1998 by UNAIDS (Joint United Nations Programme on HIV and AIDS), an organization formed two years earlier. It may be no exaggeration to assume that both the publication of this report and the choice of the publication date represented a conscious strategy on the part of UNAIDS to indicate its autonomy and to distinguish it from that of its "rival," the wHO, which had until UNAIDs's inception exercised control over AIDS policies. ${ }^{9}$ Another instance of how the symbolism of a UN day may be instrumentalized is provided by UNAIDs's 2003 decision to launch its program seeking to improve the situation in developing countries, the so-called 3 by 5 initiative, on December 1 to coincide with World AIDS Day, although the program itself had already been running since the beginning of that year. ${ }^{10}$ The UN also instrumentalizes these days to advise states on actions to tackle the seminal issues. An example is the resolution on

8 Other examples include the flagship report issued since 2017 on June 27 to mark Micro-, Small and Medium-Sized Enterprises Day and the flagship report on disability and development published since 2018 on occasion of the International Day of Disabled Persons on December 3 .

9 UNAIDs's specific focus was on surveillance and prevention. See Cueto, Marcos, Theodor M. Brown, and Elisabeth Fee. The World Health Organization: A History (Cambridge: Cambridge University Press, 2019), 222. 
the International Day of Biological Diversity, celebrated on May 22. On this day the UN invites its member states to sign and ratify the Cartagena Protocol (2003) on the protection of biological diversity.

Unlike the other types of observances, UN days reoccur annually, but it is not always easy to retain their legacy on a long-term basis. Even themes which are indispensable for the UN's mandate may temporally lose relevance to competing agendas, as an episode from the history of Human Rights Day reveals. This observance, held on December 10, constitutes one of the earliest dates added to the UN's calendar - it has taken place since 1950, to mark the day on which the Universal Declaration of Human Rights was adopted in 1948. According to the UN website: "this Day is observed all around the world with initiatives ranging from military and police officers swapping guns for running shoes in South Sudan, to a student competition in Russia, or an exhibit in Brazil."11 Crucial and symbolic events that take place on this day include the announcement of the laureate of the Nobel Peace Prize in Oslo (since 1990) and the UN prize in the Field of Human Rights awarded at five-year intervals. Moreover, in several countries, the day has acquired national significance. For example, as a symbolic gesture, President Raúl Alfonsin of Argentina decided to assume office on December 10, 1983, ending the military dictatorship that had ruled the country since 1976 . Since then all presidential inaugurations in Argentina have taken place on 10 December.

Nevertheless, as Roland Burke pointed out in his insightful blogpost, in 1973 Human Rights Day nearly fell into oblivion within the UN - a rather striking lapse because the year marked the twenty-fifth anniversary of the Universal Declaration. ${ }^{12}$ Moreover, it was precisely at this time that the UN Headquarters relinquished its Human Rights Division by moving it to Geneva. This was, both psychologically and administratively, a downgrade. So why did human rights disappear from the agenda, albeit on a temporary basis? 1973 saw the launch of the International Decade to Combat Racism and Racial Discrimination and the passing of the International Convention on the Suppression and Punishment of the Crime of Apartheid (ISCPA) at the General Assembly, merely a few days before Human Rights Day. This overshadowed Human Rights Day to such an extent that ironically, it was the Saudi Permanent Representative, one of the most ardent opponents of the original declaration in 1948, who had to remind his colleagues that 10 December was "a special occasion to be observed" and

\footnotetext{
11 https://www.un.org/en/sections/observances/why-do-we-mark-international-days/ (accessed June 30, 2019).

12 Burke, Roland. "Human Rights Day 1973: The 'Liberation' of the Universal Declaration," https://hhr.hypotheses.org/320 (accessed June 30, 2019).
} 
that the UN had scheduled various events to take place in conjunction with the event that were not to be forgotten. ${ }^{13}$

More recently UN days have been closely associated not only with human rights, but also with two frameworks that have evolved into the new normative consensus of the global community: the Millennium Development Goals (MDGs) and since 2015 the Sustainable Development Goals (SDGs). This interdependence is underlined by the premise that "human rights are driven by progress on all SDGS and the SDGs are driven by advancement on human rights." ${ }^{14}$ One advantage that may arise from this alignment is that the aspirational nature of UN days becomes strengthened if combined with more tangible targets and a certain degree of accountability. To that end, the inclusion of a number of UN days into the UN's annual planning calendar in conjunction with specific SDGs definitely bolsters their prestige. ${ }^{15}$ Moreover, the SDGs framework also provides an overarching "grand narrative" for the otherwise extremely heterogeneous issues covered by these observances. Nevertheless, both the human-rights-based framework and the more recent MDGs and SGDs-based ones are prone to abuse: for example, even some dictators have become their eager advocates. This is possible by cherry-picking some UN days and the corresponding specific objectives - for example the reduction of child mortality. Once progress is made on such narrow issues, this gives them the opportunity to "celebrate" specific achievements while covering up a notorious record of human rights violations. In that context, some scholars and political analysists have levelled criticism at the SDGs precisely because of the absence of individual rights, civil liberties and democracy from their framework. ${ }^{16}$

In light of the fundamental role which UN observances play in the UN's system and their high numbers, the absence of central oversight is surprising. In 1980 the United Nations General Assembly adopted guidelines for international years, but no such guidelines exist for international days, and "no single office within the United Nations appears to have responsibility for coordinating and overseeing the implementation of international days proclaimed by

\footnotetext{
13 Ibid.

14 https://womenalliance.org/the-universal-declaration-of-human-rights-and-accountabil ity-on-womens-human-rights (accessed June 30, 2019).

15 https://www.un.org/sustainabledevelopment/sdg-planning-calendar-2019/ (accessed June 30, 2019).

16 See for example the special issue Winkler, Inga T., and Carmel Williams, eds. "The Sustainable Development Goals and human rights: An Early Critical Review." The International Journal of Human Rights 21 (8) (2017).
} 
the various entities of the United Nations system."17 This becomes evident from a document issued by wHO on World Health Days (2017) which addresses the proliferation of requests for specialized health days at the wHO and the apparent lack of clarity about their impact. This piece provides valuable insights into some pragmatic issues that cannot be obtained from other sources and is therefore worth further exploring. It states that unlike UNESCO, which established its own procedure for approval, "the mandate for world days in wHo has been based on specific technical rationales rather than on an overall strategy or the assessment of proposals for new international days against pre-defined and pre-agreed criteria." Usually, a feasibility study is undertaken, but proposals do not have to pass through the General Assembly.

The document list over 100 observances, some of which are administered by the UN, some by the wHO, while a third category includes days which are officially organized by "others," but they are also approved by the wно. The potential benefits of these occasions for health, human rights and sustainable development are wide-ranging and may include greater public awareness and media coverage, resource mobilization, policy change and the initiation of further research. Yet, as becomes evident from the report, wHO has no standardized methods for measuring the actual impact. Moreover, the document is concerned not only with the high number of these observances, but also with the financial consequences for wHO, which struggles to secure the resources: the estimated global costs of a world day range from US $\$ 100,000$ to US $\$ 1$ million and further costs can be incurred for regional and country activities. The overabundance of these days is deemed undesirable. Recommendations in the text to reduce their number include assessments to ascertain whether their mandate is still relevant, if some of them could be combined and if there are alternative ways to achieve the desired impact. Nevertheless, it proves difficult to find benchmarks for measuring the difference that these observances can make, particularly in the longer term. Short-term results may be assessed against the volume of media coverage, citations in publications and the number of people sharing information and infographics related to these occasions on social media.

\subsection{UN Days and the Public: Digital Diplomacy}

Recent scholarship has demonstrated that the alignment of two, formerly unconnected fields of research - the history of international organizations

\footnotetext{
17 "World health days," World Health Organization, $144^{\text {th }}$ session, Provisional agenda item 7.6, Евв 144/39 Rev. 1. 15 January 2019, online access at: https://apps.who.int/gb/ebwha/ pdf_files/EB144/B144_39Revi-en.pdf (accessed June 30, 2019).
} 
and the history of the media - provides potential for revising and rethinking many of the common sense assumptions about how international organizations rely on the media to facilitate international global governance. ${ }^{18}$ This research direction, which focuses on the role of actors, actants (or technologies), audiences and activities in communication, ${ }^{19}$ is particularly concerned with the question to what extent the publicity of organizations such as the UN has been successful in fulfilling the exorbitant expectations placed upon them. The various insights that can be gleaned from this new research contest several premises that had previously usually been taken for granted in the literature. Contrary to what would appear evident at first sight, it transpires that more information does not invariably equal stronger public support; neither does it automatically generate greater legitimacy. Wider outreach in communication does not necessarily provide automatic benefits for international organizations. Moreover, awareness-raising may yield unexpected, and not always positive, side-effects, especially in the case of contested topics. ${ }^{20}$

Research in the field has been typically confined to the investigation of the role of traditional media - newspapers, radio, television, photography and film. While these genres are certainly not irrelevant for studying UN days, the "new media" and digital diplomacy have recently taken priority in communicating their message. ${ }^{21}$ As such, these observances may provide a useful lens through which to investigate how the UN has proved capable (or not) of adapting to rapid changes in the media world. One of the major problems UN communications has been facing is that irrespective of the efforts of communication professionals, what gets published, broadcast and posted on digital media is usually determined by editors, publishers and producers, and the UN itself has very limited influence on it. Moreover, given the extreme competition for media attention, and the virtually unlimited flow of information, it is difficult to fulfil the ambition to actively shape news and agendas rather than

18 For an overview: "Introduction." In International Organizations and the Media in the Nineteenth and Twentieth Centuries: Exorbitant Expectations, eds. Jonas Brendebach, Martin Herzer, and Heidi Tworek.

19 Lewis, Seth, and Oscar Westlund. "Actors, Actants, Audiences, and Activities in CrossMedia News Work." Digital Journalism 3 (1) (2015), 19-37.

20 "Introduction" in Brendebach, Herzer, and Tworek, eds., 8.

21 A standard definition of digital diplomacy is "the use of internet and information communication technology to advance diplomatic agendas." 
just reacting to events. ${ }^{22}$ Another concern is that some issues easily generate attention, whereas others (such as international criminal law and disarmament) appear to be less attractive for the public. ${ }^{23}$

Social media not only changed the temporal frameworks of diplomacy by making it more real-time, it also altered the relationship between citizens and politics. The UN was not particularly quick in embracing the digital turn, and for a long time, engagement with social media represented something of a soft task that could be relegated to interns. ${ }^{24}$ Nevertheless, in recent years the field has undergone a greater degree of professionalization. One indication of this increasing awareness is that on January 30, 2015 the UN's first ever Social Media Day took place at the New York Headquarters with the aim to contemplate the opportunities and challenges associated with digital diplomacy. ${ }^{25}$ Another indication of this awareness is that the name of the UN's Department of Public Information, whose official mandate is to promote global awareness and understanding of the UN and to interact and partner with diverse audiences, was changed, as of January 1, 2019, to Department of Global Communications. As the official notification about this change states, the new designation "anticipates the new ways of working underscoring the interactivity and co-operation in information management between the United Nations and its stakeholders." 26 Under the motto "Inform, Engage, Act," the Department places emphasis on "using the latest technology, multimedia and social media platforms to amplify the UN's message and it carries out communication campaigns on priority issues." This new name and revised remit of the Department testifies to the fundamental role which online campaigns have come to play in the UN's communication. Numerous instances in conjunction with the UN days reveal that these occasions have also provided opportunities for experimentation with novel ideas and concepts of digital diplomacy. For example, on the occasion of the World Humanitarian Day in 2017 a Twitter campaign,

22 Crossette, Barbara. "Communication and Celebrities?" In The Oxford Handbook on the United Nations, eds. Tom Weiss and Sam Daws (Oxford: Oxford University Press, 2007), 284 .

23 Ibid. $282-83$.

24 http://resources.audiense.com/blog/interview-case-study-how-the-un-united-nationsuses-twitter-social-media-to-bring-the-world-together-one-tweet-at-at-time (accessed on June 30, 2019).

25 https://blogs.un.org/blog/2015/o1/26/social-media-day-schedule-and-more/ (accessed on June 30, 2019).

26 https://outreach.un.org/ngorelations/content/new-year-new-name (accessed on June 30, 2019). 
a "living petition" was run under the hashtag \#NotATarget. The innovative element of this initiative was that in place of a signed document the petition projected people's faces, names, and locations onto screens and onto a sculpture created by an artist specifically for this UN campaign. ${ }^{27}$

To date, research into the fundamental shift that this ever-increasing reliance on social media has brought about in the communication of international organizations has remained very limited. Moreover, it is typically confined to singular case studies, revolving around one specific initiative or one social media outlet. What is evident, however, even on the basis of this scarce research, is that the commercial nature of the new sites - Facebook, Twitter, Instagram has significantly altered the ways in which the public and supporters become involved. One difference relates to temporalities - although it is possible to archive interactions, changes in the social media are rapid and the visibility of new items is only temporal. Therefore, action and reaction need to be "quick, immediate and measurable." 28 A further consequence is the constant (over) flow of information. The communication of news by the UN requires the prioritization and orchestration of different agendas with different levels of urgency. As the team leader of UN social media, Nancy Grove explained in 2015, their strategy is to create a mix between "serious" and "more uplifting" stories and messages. But what happens when in a given year International Jazz Day, which was initiated by jazz pianist and UnEsco Goodwill Ambassador Herbie Hancock and whose remit is "to promote freedom of expression, foster gender equality and reinforce the role of youth for social change," happens to coincide with an Ebola outbreak? According to Grove:

Internally, it can feel a bit inappropriate for us to be looking at something less urgent when we're highly aware there's a major event happening somewhere else in the world. But at the same time, those international days are sometimes our most popular content and a lot of people want to see it. So we try to take those more feel good stories and explain why it's worth caring about. So with that Jazz stuff we're showing how it promotes social tolerance and celebrates different arts. This coincides with our wider goals that we talk about on our accounts as appreciation for different cultures can help to deal with violent extremism. ${ }^{29}$

27 https://www.agendaforhumanity.org/news-details/10093 (accessed on June 30, 2019).

28 "Introduction." In Global Humanitarianism and the Media Culture, eds. Michael Lawrence and Rachel Tavernor (Manchester: Manchester University Press, 2019), 6.

$29 \mathrm{http} / / /$ resources.audiense.com/blog/interview-case-study-how-the-un-united-nationsuses-twitter-social-media-to-bring-the-world-together-one-tweet-at-at-time (accessed on June 30, 2019). 
Digital platforms not only have hugely increased the chances of reaching out to ordinary citizens, but also provide opportunities for involving them, as agents in their own right, in actively shaping these observances. Few people would doubt that the digital turn has created opportunities for moving away from an elitist approach towards a more inclusive framework. For example, according to the UN's Annual Water Report, it is estimated that World Water Day in 2016 involved about 500 events worldwide in over 100 countries and the social media engagement marked with the hashtag \#WorldWaterDay could reach up to 1.6 billion people globally. ${ }^{30}$ Yet, this opportunity for democratization has serious limitations, because it extends only to people who have access to the internet. Ironically and paradoxically, this situation only further increases the disadvantage of the world's poorer regions, even though it is precisely their opportunities for accessing and engaging with information that should be improved in the first place. ${ }^{31}$

Moreover, technological usage comes with various side-effects. One of these is that new media platforms provide more space for emotional manifestations of individual morality at the expense of its collective manifestations of solidarity. Some scholars identify these transformations with a new "posthumanitarian" age. According to Lillie Chouliaraki:

The tearful celebrity, the rock concert, the Twitter hype and the graphic attention are ... prototypical performances of post-humanitarianism which limit our resources for reflecting upon human vulnerability as a political problem of injustice and minimizes our capacity of empathy with vulnerable others as others with their own humanity. ${ }^{32}$

Like the media apparatus of other international organizations, by the end of the twentieth century UN media had shifted from covering institutions to reporting stories with a human interest and often involving a growing phalanx of celebrities recruited from the entertainment and sports industries. Several UN days involve the kinds of formalized alliances with celebrities that are increasingly being forged between the development sector and the

\footnotetext{
30 https://www.unwater.org/publications/un-water-annual-report-2016/ (accessed on June 30, 2019).

31 This also applies to the more general trend that the UN makes most of its documents available only online. See Brendebach, Herzer, and Tworek, International Organizations, 6 .

32 Chouliaraki, Lillie. The Ironic Spectator: Solidarity in the Age of Post-Humanism (Cambridge: Polity, 2012), 187.
} 
celebrity industry. ${ }^{33}$ One such example is participation in the long-running UN Goodwill Ambassador Scheme. FAO - the Food and Agriculture Organization of the United Nations - works with over thirty Goodwill Ambassadors who perform special tasks during World Food Day. ${ }^{34}$ They include Raul, the Spanish football star, and actress Gina Lollobrigida. ILO chose to collaborate for World Day of Social Justice with Colombian award-winning pop singer Shakira. The highest-selling South American artist of all time, Shakira grew up in an impoverished region of Colombia, so using her face can help to diversify the "white savior complex" of Hollywood A-list celebrities. ${ }^{35}$ It may not be a coincidence that the cooperation materialized during the tenure of ILO Director Juan Somavia, who is originally from Chile. Social justice activism has been traditionally strong in Latin America. Linking UN days to celebrities with "lived experiences" may result in more authentic and powerful messages. For example, John Lennon's widow, Yoko Ono is the official face of World Widows' Day, while Formula-1 Champion, Damon Hill has become the celebrity collaborator of Down Syndrome Day because his son, Ollie, is affected by the condition.

The role of music in communicating the fundamental messages of the UN has been acknowledged from its very early days. It is true that over the years the type of music, the targeted audience and setting have undergone a huge shift, as the comparison of two concerts that took place more than six decades apart reveals. On 10 December 1949 a concert was held on the occasion of Human Rights Day at Carnegie Hall in New York with the participation of the Boston Symphony Orchestra and the Collegiate Chorale, with Leonard Bernstein conducting the orchestra and Yehudi Menuhin playing the violin. One of the most illustrious guests was actor Sir Laurence Olivier who read the Preamble of the Universal Declaration and among the musical pieces played during the concert was the United Nations March by Dmitri Shostakovich. ${ }^{36}$ In 2012, one of the most successful performers and the fourth most followed person in the world on Instagram, Beyoncé, was invited to contribute to World Humanitarian Day with the song "I was Here." This number was specially composed by

33 See Brockington, Dan. Celebrity Advocacy and International Development (London and New York: Routledge 2014).

34 For a FAO brochure see: http://www.fao.org/3/a1513e/a1513eoo.pdf (accessed on June 30, 2019).

On Hollywood celebrities see Sluga, Glenda. "Hollywood, the United Nations, and the long history of film communicating internationalism." In Brendebach, Herzer and Tworek, International Organizations, 138-157.

36 The concert can be accessed via https://www.unmultimedia.org/avlibrary/asset/2146/214 6ooo/ (part 1) and https://www.unmultimedia.org/avlibrary/asset/2146/2146001/ (part 2) (accessed on June 30, 2019). 
American songwriter Diana Warren for this purpose and it sought to convey the message that everyone can become a hero and that even the smallest deeds matter. Beyoncé's official performance video was set in front of an audience at the United Nations General Assembly hall, and the singer performed in the midst of "a stunning multimedia array" of images of people in conflict: desperate people queuing for water at a relief truck, starving children receiving a mouthful of food, and aid workers in tears holding children. ${ }^{37}$ The music video was released on 19 August to mark the UN day. It is estimated to have reached around one billion people, and participants in the ensuing online debate included Barack Obama, Lady Gaga, Oprah and Justin Bieber.

To what extent could these concerts genuinely contribute to the promotion of human rights and humanitarianism? With regards to the concert of 1949, it is telling that the front-page headers of the New York Times on the day after the concert made no reference to human rights at all. Instead, they were concerned with topics such as the imminent Indonesian independence and the negotiations that led towards the establishment of NATO. ${ }^{38}$ Historian Mark Bradley argued that this void provides proof that this period was not, as Churchill famously claimed, about "the enthronement of human rights." Rather, the world order was shaped by the narratives of the Cold War and decolonization. Beyoncé's concert was met with a great deal of criticism in the media. For example, journalist Michael Wolff in the Guardian called the event a "puffery PR occasion" with an undefined goal. ${ }^{39}$ Wolff drew a parallel between Beyoncés performance and the archetypical example of "promotable nebulous altruism" of the 1985 We are the World campaign, the fund-raising event seeking to alleviate the impact of the famine in Ethiopia. He found that the main effect of both was to promote the music industry.

While Beyoncé's performance represents merely one, albeit paradigmatic, instance of the instrumentalization of celebrity diplomacy in conjunction with UN days, the concerns it raises have broader relevance for international organizations' reliance on the media and celebrity involvement. It is common

37 https://teachrock.org/lesson/everyday-heroes-beyonce-united-nations-world-humani tarian-day/ (accessed on June 30, 2019). As this site reveals, the song is also used for the purposes of human rights education.

38 Bradley, Mark. The World Reimagined:Americans and Human Rights in the Twentieth Century (New York: Cambridge University Press, 2016), 16.

39 Wolff, Michael. "What good will World Humanitarian Day do?," The Guardian, August 13, 2012, https://www.theguardian.com/commentisfree/2012/aug/13/what-good-will-worldhumanitarian-day-do (accessed on June 30, 2019). 
knowledge that media have played a central role in the process of the redefinition of the contours of humanitarian identity since the end of the Cold War. ${ }^{40}$

The increasing celebrity involvement is deemed to have created "a hegemonic culture of humanitarianism in which the humanitarian intention becomes overridden by celebrity identity and moral responsibility is based on pity rather than the demand for justice." ${ }^{41}$ Moreover, celebrity involvement in UN days in most cases appears to involve a tendency that has been described as the disentanglement between the public and politics across the global North and South. ${ }^{42}$ Producers and consumers of celebrity humanitarianism typically reside in the North, whereas the problems to be tackled are usually identified with the South. This leads to the undesired effect whereby people in the South are being pushed into the category of the "distant other." The awareness-raising potentials of digital diplomacy for the purposes of UN days are evident. What remains to be seen is, however, to what extent activism can be translated into action with a true potential to change the status quo and whether UN days can serve as a platform from which to initiate new narratives about justice and development.

\subsection{The Public and UN Days: towards the Fourth UN}

UN observances have been characterized as designators of the contours of a normative system for the imagined global community and as products of the institutionalization and bureaucratization of global virtue. ${ }^{43}$ The continuously evolving agenda of international days is actively shaping political ideas and global norms, at times acting as unifying, centripetal forces, while on other occasions as splintering, centrifugal forces. One of the most striking phenomena, which becomes evident when investigating the driving forces behind UN days, what their motivations may be, how are they related to the $\mathrm{UN}$ and what impact they exert is the prevalence of agents and ideas brought in from outside the UN. In fact, if we are to give these contributions more visibility and due recognition, the existing analytical frameworks may prove not entirely adequate.

40 Barnett, Michael, and Thomas G. Weiss, eds. Humanitarianism in Question: Power, Politics and Ethics (Ithaca NY: Cornell University Press), 2.

41 Müller, Tanja. "The Long Shadow of Band Aid Humanitarianism: Revisiting the Dynamics Between Famine and Celebrity." Third World Quarterly, 34 (3) (2013), 470.

42 See Richey, Lisa Ann, ed. Celebrity Humanitarianism and North-South Relations: Politics, Place and Power (London and New York: Routledge, 2016).

43 Drori, Gili S. “United Nations' Dedications: A World Culture in the Making?" International Sociology 20 (2) (2005), 189 . 
A suitable point of departure for revising the appropriate analytical toolkit may be the existing categorizations. Traditionally, analysts have distinguished two interdependent United Nations: the first one comprising the member states and the other one comprising the secretariats. ${ }^{44}$ Both play indispensable roles in the facilitation of UN days: regardless of where the proposal for a new observance originates, it can be realized only if at least one member state - a contributor from the "First UN" - officially supports the initiative. The role of the "Second UN" - the secretariats - includes, among other things, the administering, communication and promotion of these events. More recently, Thomas G. Weiss, Tatiana Carayannis and Richard Jolly have emphasized the substantial role of non-state actors, comprising institutions and individuals that are closely aligned with the UN, but officially do not form part of it: they constitute the "Third UN." 45 These "outside-insiders" include NGOs, independent commissions, experts and academics who are not on the regular payroll of a government or a secretariat. They are associated with the UN through informal networks and they have often helped to push forward "ideas, policies, priorities and practices" which were originally not deemed desirable by representatives of the First and the Second UN. Their fields of activity include advocacy, policy analysis and idea-mongering, and they regularly shape new policies and help mobilize public opinion. As the authors put it: "what once seemed marginal for international relations now is central to multilateralism." 46 This trend has become even more pronounced since the 1970 s, as a consequence of the process which is commonly referred to as the "NGO-ization" of international relations. ${ }^{47}$

UN days provide very strong evidence of the substantial role of such nonstate actors. Among the numerous examples is one which also demonstrates that one single individual's idea can make a difference. World Widows' Day, observed since 2010 on June 23, was the brainchild of Raj Loomba, a businessman of Indian descent living in Britain. In 1997 he established an NGO, the Loomba Foundation, with the remit to call attention to the discrimination that

44 Claude, Inis L. Jr. "Peace and Security: Prospective Roles for the Two United Nations." Global Governance 2. (3) (1996) 289-298.

45 Weiss, Thomas G., Tatiana Carayannis and Richard Jolly. "The 'Third' United Nations." Global Governance 15 (2009), 123-142.

46 Weiss, Thomas G. What's Wrong with the United Nations and How to Fix It (Cambridge: Polity Press, 2012).

47 See Irye, Akira. Global Community: The Role of International Organizations in the Making of the Contemporary World (Berkeley, CA: University of California Press, 2002). 
widows and their children are facing in India and other parts of the world. ${ }^{48}$ Loomba was motivated by his childhood experiences in India; after tuberculosis had killed his father in 1954, Loomba, as a ten-year-old boy, was compelled to observe the grim transformation in his mother's life as she became entirely marginalized and stigmatized in her community. The NGO foregrounded the prospect of the UN day by introducing the idea to the House of Lords in 2006, recruiting Cherie Blair for the campaign and launching a five-year awarenessraising campaign with the target to achieve endorsement from the UN. The observance was officially approved in 2010 because the General Assembly was "deeply concerned that millions of children of widows face situations of hunger, malnutrition, child labour, difficult access to health care, water and sanitation, loss of schooling, illiteracy and trafficking in persons." ${ }^{\text {"9 }}$

On other occasions a new proposal for a UN day has been motivated not by placing a new cause on the agenda, but by the chance to provide a better venue for an issue that was already being addressed in a different format. As has been shown above, in the World Health Organization's document, the proliferation of UN days - and particularly in the field of health, disease and disability - has been identified as a concern. It therefore took strenuous lobbying to obtain approval for World Down Syndrome Day, which was initiated by Down Syndrome International at its conference held in Majorca in 2005. The main motivation for this was a paradox that also serves as a good indication of the North-South divide. Since 1981 such international congresses have been organized on a biannual basis, but typically only participants from Western, affluent countries were able to afford to take part. Ironically, these also happen to be the regions with the lowest ratio of children born with Down syndrome (due to the widespread availability of prenatal testing), whereas developing countries have the highest ratio. ${ }^{50}$ The new UN day can accommodate numerous events across the globe and connect people virtually, and this can go some way towards addressing the "outreach deficit" of the conferences. ${ }^{51}$

The list of UN days initiated and supported by representatives of the "Third UN" with diverse motivations could be further continued, but it is even more noteworthy that especially some recently approved observances have been

48 https://www.theloombafoundation.org/about/our-story and https://www.theloomba foundation.org/sites/default/files/2019-06/Loomba2o_text_3.6.3-webview.pdf (accessed June 30, 2019).

49 For the resolution see https://undocs.org/A/RES/65/189 (accessed June 30, 2019).

5o Interview with Dr. Balbir Singh, representative of Down Syndrome International, National University of Singapore, November 12, 2019.

$5^{1} \quad$ For the resolution see https://undocs.org/A/RES/66/149 (accessed June 30, 2019). 
instigated by groups and individuals who are complete outsiders to the UN and - at least initially - they did not have privileged access to resources that a more formalized relationship with the UN and its agencies can deliver. Take for example World Bee Day, a grassroots initiative of some members of the Slovenian Beekeepers' Association whose motivation was twofold: on the one hand, to gain acknowledgement of the distinguished role of bees and beekeeping in Slovenian culture; on the other, the global concern for preserving the entire ecosystem and natural biodiversity. ${ }^{52}$ The local aspect of this initiative was recognized through the choice of May 20 for this UN observance, which coincides with the birthday in 1734 of Anton Jansa, a pioneer of modern apiculture from Carniola (today part of Slovenia) and a teacher at the Habsburg court of Vienna. It is true that the success of the initiative - the resolution was accepted in December 2017 after a three-year awareness-raising campaign - depended not only on the significance of the cause and the enthusiasm and perseverance of its initiators, but also on the support it received from Slovenia's Deputy Prime Minister and Minister for Agriculture, Forestry and Food, in other words, from the "First UN."

Without such support the road to obtaining approval for a grassroots initiative may take longer and face more obstacles, as the case of Leszek Sibilski, a Polish-born professor now living in the United States, reveals. Sibilski led a campaign with his sociology students to promote a resolution for World Bicycle Day, which was accepted in $2018 .{ }^{53} \mathrm{~A}$ former member of the Polish national cycling team and the holder of a PhD in Applied Sociology specializing in Social Action and Social Movements, Sibilsksi promoted his initiative by writing blogposts as well as giving a presentation at a symposium in Taipei where he formally made a case for the proposed day. His first attempt to gain the support of a UN ambassador representing "one of the most bicycle-friendly nations in earth" proved unsuccessful and the rejection led to the loss of the already existing support from other organizations. ${ }^{4}$ Sibilski then received the strategic advice to look for a country that promotes sustainable mobility as a whole, rather than just the use of bicycles. He subsequently approached the representatives of Turkmenistan's Permanent Mission to the UN in New York in the knowledge that the country had hosted the first-ever global conference

$5^{2}$ https://bestculturaldestinations.com/blog/slovenian-beekeepers-to-world-hives-holdthe-secret-to-harmonious-living (consulted June 30, 2019), for the resolution see https:// undocs.org/A/RES/72/211 (accessed June 30, 2019). pen?CID=TAI_TT_Transport_EN_EXT (accessed June 30, 2019). 
on sustainable transport and successfully sponsored resolutions pertaining to transport at the UN. This time, his strategy yielded success.

Last but not least, it may be worth considering an observance, the International Day of Action Against McDonald's, which is not officially endorsed by the UN. Quite the contrary, in a certain sense it acts as a counter-initiative to World Food Day. ${ }^{55}$ Both events take place on October 16, the day on which FAO - the UN's Food and Agricultural Organization - was founded in 1945. World Food Day offers insight into how an observance could be instrumentalized for political purposes during the Cold War. It was approved by the UN in 1979, upon the proposal of Hungarian Minister of Agriculture, Pál Romány. Much as Romány was concerned with world hunger, his direct political motivation was to garner international support for Hungary. The country had rejoined the FAO in that period after decades of inactivity, in line with a new domestic policy called the new economic mechanism, and this move was viewed with suspicion on the part of the Soviet Union and the GDR. ${ }^{56}$

Since 1985, on World Food Day an alternative event has been organized in several places across the globe: Anti-McDonald's Day, which was initiated by London Greenpeace - an organization that predates Greenpeace and is unrelated to it. ${ }^{57}$ The following year, members Helen Steel and Dave Morris, a gardener and a postman, started to hand out a factsheet "What is wrong with McDonald's?" for which they were taken to court by McDonald's and this led to the infamous McLibel case, allegedly the longest ever libel trial in British history. ${ }^{58}$ Members of the group were later joined by the initiative Food not Bombs, which included the sharing of free vegan burgers outside McDonald's on World Food Day and expressing solidarity with those on trial. ${ }^{59}$ The fifteenth anniversary in 1999 saw 425 local protests in 23 countries. ${ }^{60}$ This anti-McDonald's grassroots initiative consciously mimics the official script of the UN days it is seeking to contest. For example, although its very ambition is to subvert global action, it not only appropriates the rationale, but also applies the wording of UN declarations as the following excerpt reveals: "the movement is dedicating

\footnotetext{
55 http://www.fao.org/world-food-day (accessed June 30, 2019).

$5^{6}$ Romány, Pál, “Legyen mindenki jóllakott?” Gazdálkodás $5^{2}$ (4) (2008), 308. http://ujsag .szie.hu/node/950 (accessed June 30, 2019).

57 The organization has existed since the 1970s, and it focuses on environmental and social justice issues.

$5^{8}$ http://www.bushywood.com/mcdonalds_libel_case.htm, and http://www.mcspotlight .org/case/trial/story.html (accessed June 30, 2019).

59 http://www.foodnotbombs.net/world_food_day_action.html (consulted on 30 June 2019).

6o Reid, Jennifer I. M., ed. Religion and Global Culture: New Terrain in the Study of Religion and the Work of Charles H. Long (Oxford: Lexington Books, 2003), 154.
} 
this annual event to a protest against the promotion of junk food, the unethical targeting of children, exploitation of workers, animal cruelty, damage to the environment and the global domination of corporations over our lives." ${ }^{61}$ Precisely because this initiative is so closely aligned with a UN day, even if by turning its remit upside down, it appears to be justified to assess it in conjunction with the UN's framework. Critical attitudes and protests also provide evidence of the dynamic and influential nature of these observances.

Taken together, the three UNs are deemed to perform eight roles collectively. These include: providing a forum for debate, generating ideas and policies, legitimating ideas and policies, advocating for ideas and policies, implementing or testing ideas and policies in the field, generating resources to pursue ideas and policies, monitoring progress in the march of ideas and the implementation of policies, and occasionally burying ideas and policies. ${ }^{62}$ Yet, as the above-mentioned instances reveal, under certain circumstances, some of these roles can be undertaken by agents who are not "outsider-insiders" but complete outsiders to the UN. They too, can act as norm entrepreneurs and agenda setters and they too contribute to the UN's "multilateral marketplace of ideas." ${ }^{3}$ In order to create space for these actors who may remain invisible if assessed through the existing analytical frameworks, it may prove useful to move beyond the threefold distinction and designate a separate category, the "Fourth UN" to allow acknowledgement of the contribution of these genuine outsiders.

It has been argued that in several fields the UN has been ahead of the curve because it promoted and successfully raised consciousness for novel ideas, including the domain of sustainable development. As even a quick glance at the themes of UN days reveals, the most striking shift that has occurred since the 1990 s is the growing emphasis on environmental issues. ${ }^{64}$ The instances above indicate that this "environmental shift" was facilitated not merely by expert groups closely aligned with the UN, but also by representatives of the global public. Traditionally, the progressive nature of the some of the ideas promoted by the UN has been measured by the number of Nobel Prize winners involved

61 Drori, “United Nations' Dedications," 189 and http://www.mcspotlight.org/new97-99.html (accessed June 30, 2019).

62 Weiss, Carayannis, and Jolly, "The 'Third' United Nations," 128-29.

63 Emmerij, Louis, Richard Jolly and Thomas G. Weiss. Ahead of the Curve? UN Ideas and Global Challenges (Bloomington: Indiana University Press, 2001), 11.

64 Hadley, Ruth. A Year to Tolerate Tolerance? An Analysis of the UN 'Year of Tolerance' in the Context of the Theoretical Debate on Tolerance, 1945-2010, PhD Thesis (Faculty of Humanities, University of Manchester, 2012), 39. 
in the relevant initiatives. But the momentum of new ideas needs to be sustained and they also must be translated into policy. It would be a mistake to ignore the contribution "outsiders" can make not only by broaching novel ideas, but also by helping to sustain heightened commitment to already ongoing developments.

The aim of this article has been to highlight the potential that a more thorough engagement with the United Nations' observances, and particularly UN days, can provide for nuancing and revising our understanding of diplomatic history and to indicate fruitful areas for further work. Even a preliminary analysis indicates that the scrutiny of UN days has the potential to contest several binaries, such as the UN of governments versus the UN of the people, insiders versus outsiders and top-down versus bottom-up action. As has been revealed, paying more attention to UN days may throw new light on the role of nonstate actors and their quasi-official and unofficial contributions to diplomacy. This intention aligns with the objective to investigate events not so much as "markers of world history," but to focus on the "latent personal and impersonal forces" behind those events. ${ }^{65}$ Moreover, it contributes to the goal of investigating diplomacy as "an extension of social interests, forces, environments," whose sites may be New York or Geneva, but also the Slovenian forests or the realm of the virtual world. Expanding the focus of analysis to the examination of how the UN communicates with outsiders in the twenty-first century and how the hitherto unacknowledged diverse group of outsiders contribute to the UN may inspire us to write more outward-looking histories of international organizations.

65 Scott-Smith, Giles, and Kenneth Weisbrode. "Editorial." Diplomatica: A Journal of Diplomacy and Society 1 (1) (2019), 2. 